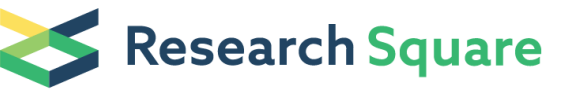 \\ Preprints are preliminary reports that have not undergone peer review. \\ They should not be considered conclusive, used to inform clinical practice, \\ or referenced by the media as validated information.
}

\section{Hyaluronate-based Self-stabilized Nanoparticles for Reverting Immunosuppression and Immunochemotherapy in Osteosarcoma Treatment}

\section{Yi Zhang}

Jiangsu Province Hospital and Nanjing Medical University First Affiliated Hospital

\section{Tao Yuan}

Jiangsu Province Hospital and Nanjing Medical University First Affiliated Hospital

\section{Zuxi Li}

Jiangsu Province Hospital and Nanjing Medical University First Affiliated Hospital

Chunyang Luo

Jiangsu Province Hospital and Nanjing Medical University First Affiliated Hospital

\section{Yuxuan Wu}

Jiangsu Province Hospital and Nanjing Medical University First Affiliated Hospital

\section{Jiyong Zhang}

Jiangsu Province Hospital and Nanjing Medical University First Affiliated Hospital

\section{Xiao Zhang}

Jiangsu Province Hospital and Nanjing Medical University First Affiliated Hospital

Weimin Fan ( $\nabla$ fanweimin@vip.sina.com )

Jiangsu Province Hospital and Nanjing Medical University First Affiliated Hospital

https://orcid.org/0000-0001-6897-9452

\section{Research}

Keywords: nanotechnology, responsive drug release, immunogenic cell death, dendritic cells maturation, macrophage polarization, immune response

Posted Date: December 2nd, 2020

DOl: https://doi.org/10.21203/rs.3.rs-118222/v1

License: (c) (1) This work is licensed under a Creative Commons Attribution 4.0 International License.

Read Full License 


\section{Abstract}

Background: Chemotherapy and immunotherapy are the mainly non-surgical treatment for osteosarcoma in clinic presently. However, serious side effects, short blood circulation time, and immunosuppressive tumor microenvironment have extremely limited their application. To generate an onsite combined chemotherapy and immunotherapy regimen, we designed a self-stabilized hyaluronic acid (HA) nanoparticle for the tumor-targeting delivery of doxorubicin (DOX), cisplatin (DDP), and resiquimod (R848) in osteosarcoma treatment, referred to as ${ }^{\mathrm{DDP}} \mathrm{NP}_{\mathrm{DOX} \& \mathrm{R} 848}$.

Methods: Here, we tested the physicochemical properties of and the ability of ${ }^{D D P} \mathrm{NP}_{\text {DOX\&R848 }}$ to induce immunogenic cell death (ICD) and revert immunosuppressive cells were characterized in vitro. The therapeutic efficacy of ${ }^{D D P} \mathrm{NP}_{\text {DOX\&R848 }}$ in vivo was evaluated in an orthotopic osteosarcoma mouse model. Furthermore, we also verified the immune memory evoking effect of ${ }^{D D P} \mathrm{NP}_{\text {DOX\&R848 }}$ in an osteosarcoma rechanllenge mouse model.

Results: ${ }^{\text {DDP }}$ NP $_{\text {DOX\&R848 }}$ possesses a uniform size (similar to $190 \mathrm{~nm}$ ) and ideal pH responsibility, and its ability to induce ICD and modulate immune cells was also proven. In vivo, regardless of the mouse model used (i.e., orthotopic osteosarcoma or rechanllenge xenografted osteosarcoma), ${ }^{D D P}{ }_{N P_{\text {DOX\&R848 }} \text { showed }}$ significantly enhanced tumor inhibition and prolonged survival. Evoked tumoricidal immune memory responses were also demonstrated in the rechanllenged osteosarcoma mouse model.

Conclusion: In summary, this intelligent codelivery platform might be a competitive candidate for osteosarcoma immunochemotherapy.

\section{Background}

Osteosarcoma is one of the most common malignancies in children and adolescents and is characterized by rapid development, high metastasis and recurrence rates, and low survival rates [1-3]. Since chemotherapy is the predominant supplementary treatment for the surgical treatment of osteosarcoma, the survival rate of osteosarcoma patients has increased. However, the inevitable serious side effects and poor therapeutic responses of patients with metastatic or relapsed osteosarcoma have long been disappointing.

Nanotechnology-based drug delivery systems (DDSs) have received much attention in cancer treatment due to their validated ability to accurately deliver drugs to tumor sites [4-6]. Through optimizing the drug distribution in vivo, DDSs, especially DDSs functionalized with active tumor-targeting ability or stimuliresponsiveness, could effectively enhance the antitumor effect and significantly reduce system toxicity compared to free chemotherapy drug administration [7-9]. Encouragingly, in our previous study, we successfully designed a self-stabilized DDS based on hyaluronic acid (HA), which has been proven to have excellent performance in the codelivery of doxorubicin (DOX) and cisplatin (DDP) and in suppressing K7M2 osteosarcoma xenografts [10]. However, subject to the dose-dependent cytotoxicity of 
chemotherapy drugs, these DDSs loaded with chemotherapy drugs demonstrated unsatisfactory performance for long-term tumor inhibition and tumor recurrence prevention. Moreover, the tumorcombating process based on chemotherapy seems to be a passive process of the body, which usually fails to activate its own "defense system". In fact, these issues can hardly be solved for DDSs with single chemotherapy drug loading and will extremely limit their further application.

Recently, immunotherapy has been regarded as a more efficient and thorough method to treat cancer by activating the innate and adaptive immune systems $[11,12]$. In contrast to the toxicity-dependent tumor inhibition of chemotherapy, immunotherapy is devoted to activating the dampened immune system to induce durable and cascading antitumor immune responses [13-15]. Furthermore, increasing positive evidence has shown that an ingenious combination of chemotherapy and immunotherapy could further enhance antitumor efficiency. However, similar to chemotherapy agents, with increasing clinical administration, a growing number of immune-related adverse events have attracted attention, some of which are serious or result in fatal outcomes $[16,17]$. Fortunately, the diverse nanosized drug carriers available might be promising prospects for the development of immunotherapy [18-20]. Therefore, it is of vital significance to encapsulate appropriate chemotherapy and immunotherapy agents in a welldesigned drug nanocarrier to deliver an in situ combination of chemotherapy and immunotherapy.

In this study, resiquimod (R848), an agonist of Toll-like receptor 7 (TLR7) and TLR8, was used as the immunotherapy agent to incorporate in our proven chemotherapy drug-loaded DDS based on HA. Thus, an HA-based, DDP-crosslinked, DOX- and R848-loaded nanocarrier (named ${ }^{D D P}{ }^{N P} P_{\text {DOx\&R848) }}$ was designed for drug delivery in osteosarcoma immunochemotherapy. DOX was first assembled with HA as described in our previous report ( $\left.\mathrm{NP}_{\text {DOX }}\right)$ [21]. To incorporate R848 in this platform, R848 was bound to poly-Lhistidine ( $\mathrm{pHis}$ ) through hydrophobic interactions to obtain a positive surface potential $\left(\mathrm{NP}_{\mathrm{R} 848}\right)$. The heavy potential difference between $\mathrm{NP}_{\mathrm{DOX}}$ and $\mathrm{NP}_{\mathrm{R} 848}$ drives the encapsulation of $\mathrm{NP}_{\mathrm{R} 848}$. Next, DDP was loaded into the system through chelation. Additionally, the crosslinking process of DDP is similar to a "locking" procedure, which can markedly enhance the stability of the nanocarrier. However, when ${ }^{D D P} \mathrm{NP}_{\mathrm{DOX} \& \mathrm{R} 848}$ is exposed to an acidic environment, such as tumor microenvironment (TME), the reduced ionization of the HA carboxyl groups and the pHis imidazole group will induce accelerated drug release. DOX and DDP are two of the most common chemotherapy drugs in osteosarcoma treatment [22-24], and they were used as a chemotherapy drugs couple in this study in comparison with the immunochemotherapy agents (R848). Moreover, as a representative anthracycline antibiotic, DOX is able to induce the immunogenic cell death (ICD) of tumor cells, which can facilitate the exposure of tumorassociated antigens (TAAs) from cells $[25,26]$. Interestingly, R848 is reported to be an immunomodulator due to its ability to remodel the TME by dendritic cell (DC) maturation and tumor-associated macrophage (TAM) reeducation $[27,28]$. Matured DCs (mDCs) can present released TAAs to native T cells to trigger the immune response. Then, the stimulated immune system will induce the proliferation of immune cells (mainly T cells) effectively and recruit these cells to the tumor site for tumor suppression. Additionally, through the R848-mediated reeducation process, TAMs can be converted from a tumor-supportive phenotype to a tumoricidal phenotype. These tumoricidal TAMs can also enhance antitumor 
immunotherapy efficacy by releasing proinflammatory factors, inducing stromal destruction and normalizing the tumor vasculature [29,30]. Furthermore, the activated immune system can help the body systemically eliminate tumors and develop a specific immune memory. These findings are of vital significance in preventing tumor metastasis and recurrence.

To confirm our hypothesis, we performed a series of experiments in vitro and in vivo. ${ }^{\text {DDP }}$ NP $_{\text {DOX\&R848 }}$ demonstrated a uniform and stable structure, specific $\mathrm{pH}$ responsiveness, and robust induction of DCs maturation and TAM reeducation in vitro. In vivo, ${ }^{\text {DDP }} \mathrm{NP}_{\text {DOX\&R848 }}$ exhibited obviously increased accumulation at the tumor site compared with free drugs. We also tested the effect of ${ }^{D D P}{ }^{N P} P_{\text {DOx\&R848 }}$ against osteosarcoma in a K7M2 orthotopic osteosarcoma mouse model. As we hypothesized, ${ }^{\mathrm{DDP}} \mathrm{NP}_{\mathrm{DOX} \& \mathrm{R} 848}$ greatly diminished tumor growth, increased the survival rate, and reduced lung metastasis. The induced anticancer immune responses were clearly investigated by immunofluorescence (IF) analyses. Moreover, the excellent performance of ${ }^{D D P}{ }_{N P}$ DOx\&R848 on immune memory evocation has also been verified in a K7M2 tumor rechallenging experiment. Overall, ${ }^{D D P}{ }_{N P}$ DOX\&R848 is a potential strategy to treat osteosarcoma through the synergy of chemotherapy and immunotherapy.

\section{Results And Discussion}

\section{Preparation and characterization of ${ }^{D D P}{ }^{N P} P_{\text {DOX \&R848. }}$}

${ }^{\text {DDP }} \mathrm{NP}_{\text {DOX \&R848 }}$ was fabricated in three steps: 1 . synthesizing $\mathrm{NP}_{\mathrm{R} 848}$ by a nanoprecipitation method; 2 . assembling $\mathrm{HA}, \mathrm{DOX}$, and $\mathrm{NP}_{\mathrm{R} 848}$ through electrostatic interactions; and 3. introducing DDP to complete the crosslinking process. In the first step, R848 was modified with pHis. Because of its branched imidazole group and amidogen group, $\mathrm{pHis}$ is a suitable material with $\mathrm{pH}$-dependent amphoteric properties and a positive surface charge. As shown in Fig. 1a and c, the resulting $\mathrm{NP}_{\mathrm{R} 848}$ nanoparticles had a uniform size of $115 \mathrm{~nm}$. Next, to verify whether there was a sufficient potential difference between $\mathrm{NP}_{\mathrm{R} 848}$ and $\mathrm{NP}_{\text {DOX }}$ to drive their assembly in the second step, the zeta potentials of $\mathrm{NP}_{\mathrm{R} 848}$ and $\mathrm{NP}_{\mathrm{DOX}}$ were measured. As shown in Fig. 1e, the zeta potentials of $\mathrm{NP}_{\mathrm{R} 848}$ and $\mathrm{NP}_{\mathrm{DOX}}$ were $43.7 \pm 2.8$ and -21.5 $\pm 1.6 \mathrm{mV}$, respectively. The large charge difference ensured a stable combination of $\mathrm{NP}_{\text {DOX }}$ and $\mathrm{NP}_{\mathrm{R} 848}$. The zeta potentials of ${ }^{D D P}{ }_{N P} P_{D O X \& R 848}$ were also tested $(-15.6 \pm 2.8 \mathrm{mV})$. The slightly negative surface charge of ${ }^{D D P} \mathrm{NP}_{\mathrm{DOX} \& \mathrm{R} 848}$ contributed to a decrease in its nonspecific interactions with serum proteins, which would facilitate its longer circulation time and tumor accumulation [31]. For a more compacted and stable construction, DDP was added to accomplish the third crosslinking step, which helped to effectively secure the cargos. As shown in Fig. $1 \mathrm{c}$, the hydrodynamic diameter $\left(D_{\mathrm{h}}\right)$ of ${ }^{\mathrm{DDP}} \mathrm{NP}_{\mathrm{DOX} \& \mathrm{R} 848}$ was $192 \mathrm{~nm}$. The morphology of DDP ${ }^{N P_{\text {DOX\&R848 }}}$ was also verified by transmission electron microscope (TEM) (Fig. 1b). To evaluate the stability of ${ }^{D D P} \mathrm{NP}_{\text {DOX\&R848 }}$ under physiological conditions, its size and zeta potential changes were measured in 10\% FBS solution (Fig. 1d). Within 3 days, no significant size or zeta

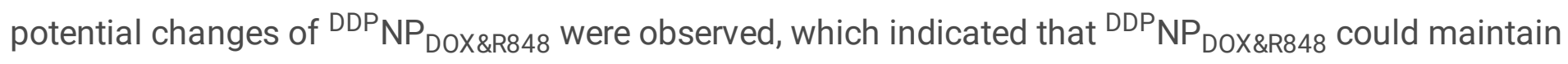


its structure under physiological conditions for a long time. The outstanding stability under physiological

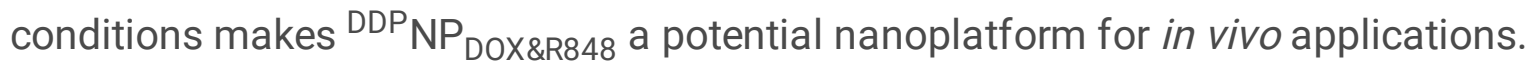

Then, to evaluate the drug release profile of ${ }^{D D P} \mathrm{NP}_{\text {DOX\&R848 }}$ in vitro, $\mathrm{PBS}$ at $\mathrm{pH} 7.4,6.5$, and 5.5 was used to mimic the $\mathrm{pH}$ of physiological, intertumoral, and intracellular microenvironments, respectively. As shown in Fig. $1 \mathrm{f}$, at pH 7.4, only $48.3 \pm 6.7 \%$ of DOX was released within $72 \mathrm{~h}$. At pH 6.5 and 5.5, the percentage of released DOX was $73.3 \pm 4.1 \%$ and $88.1 \pm 5.7 \%$, respectively, within $72 \mathrm{~h}$. Compared with DOX release at physiological $\mathrm{pH}$, the release of DOX in an acidic environment was accelerated. Moreover, the release of $\mathrm{R} 848$ from ${ }^{\mathrm{DDP}} \mathrm{NP}_{\mathrm{DOX} \& \mathrm{R} 848}$ also demonstrated pH-dependent behavior (Fig. $1 \mathrm{~h}$ ). At pH 5.5, $96.5 \pm 4.0 \%$ of R848 was released within $72 \mathrm{~h}$, which was 3.0 and 1.1 times higher than that at $\mathrm{pH} 7.4$ and 6.5 , respectively. Unsurprisingly, the loaded DDP was released in a pH-dependent manner similar to that of DOX or R848 (Fig. 1g). The promising pH response of ${ }^{D D P} \mathrm{NP}_{\text {DOX\&R848 }}$ was due to its chemical structure. On the one hand, the ionization degree of HA carboxyl groups was reduced in acidic environments, which disrupts the electrostatic adsorption between HA and DOX. On the other hand, as pHis is a pH-dependent amphoteric biomaterial, the abundant imidazole groups result in a maximum response to a hydrophobicto-hydrophilic switch at $\mathrm{pH}$ 6.5. This characteristic benefits $\mathrm{R} 848$ release from the $\mathrm{NP}_{\mathrm{R} 848}$ core under acidic conditions. Generally, ${ }^{\text {DDP }} \mathrm{NP}_{\mathrm{DOX} \& 848}$ was proven to have a uniform and stable structure, valid drug coencapsulation, and an appropriate $\mathrm{pH}$ sensitivity for drug release.

\section{Tumor cell uptake and cytotoxicity.}

The uptake of ${ }^{D D P} N P_{\text {DOX\&R848 }}$ by K7M2 tumor cells was identified by FCM. As Fig. $2 b$ shows, after $1 \mathrm{~h}$ of incubation with DOX or ${ }^{D D P} \mathrm{NP}_{\text {DOX\&R848, }}$, the fluorescence of DOX could be detected in tumor cells in each group. However, the signal intensity in the DOX-treated group was obviously higher than that in the ${ }^{\mathrm{DDP}} \mathrm{NP}_{\mathrm{DOX} \& \mathrm{R} 848}$-treated group. When the incubation time was extended to $6 \mathrm{~h}$, the intensity of DOX fluorescence in the two groups showed a conspicuous increase, and more importantly, the fluorescence intensity of DOX in the ${ }^{D D P} \mathrm{NP}_{\mathrm{DOX} \& \mathrm{R} 848}$ group was very close to that in the DOX group. This effect might be attributed to the distinct uptake methods of free small molecule drugs and the drug-loaded nanocarrier. Free DOX, as a small molecular drug, is taken up by cells through free diffusion and has an ultrahigh uptake efficiency before reaching a steady state. However, ${ }^{D D P} \mathrm{NP}_{\text {DOX\&R848 }}$ is taken up by tumor cells by endocytosis, which is characterized by its slow uptake rate. These properties led to the different uptake efficiencies in the early and later periods. Moreover, the uptake of drugs was also analyzed by fluorescence microscopy (Fig. 2a). Consistent with the FCM results, compared to DOX uptake, the uptake process of ${ }^{D D P} \mathrm{NP}_{\mathrm{DOX} \& \mathrm{R} 848}$ was more moderative and complex. The DOX fluorescence intensity in the ${ }^{D D P} N_{\text {DOX \& } 848}$ group was obviously lower than that of the DOX group after $1 \mathrm{~h}$ of incubation. Moreover, DOX fluorescence was observed in the cell nucleus in the DOX groups, while it was mainly located in the cytoplasm in the ${ }^{\text {DDP }} \mathrm{NP}_{\text {DOX\&R848 }}$ group. However, when the incubation time was prolonged to $6 \mathrm{~h}$, the DOX fluorescence intensity increased in all groups, and the DOX signal in each group was detected in the 
nucleus. The spatial and temporal disparities in the DOX signal might be attributed to the different methods by which tumor cells take up free small molecule drugs and drug-loaded nanocarriers.

The cytotoxicity of ${ }^{D D P} \mathrm{NP}_{\text {DOx\&R848 }}$ was also analyzed in vitro. As shown in Fig. 2c, R848 failed to influence the proliferation of tumor cells when used alone or loaded in pHis nanoparticles $\left(\mathrm{NP}_{\mathrm{R} 848}\right)$. ${ }^{\text {DDP }}$ NP $_{\text {DOX\&R848 }}$ exhibited an effect similar to that of DOX + DDP, ${ }^{D D P}{ }_{N P}$ DOX , or DOX + DDP + R848 in suppressing K7M2 cell proliferation, which indicated that the co-delivery of DOX, DDP, and R848 have no obviously influence on the cytotoxicity of DOX and DDP (Fig. $2 \mathrm{~d}$ and e).

\section{ICD inducing in vitro.}

The ICD of tumor cells is a special autophagy pathway that triggers TAA release and antigen-specific immune response [25]. ICD is characterized by the exposure of calreticulin (CALR) on the cell surface, which serves as an "eat me" signal and can significantly promote the phagocytosis of TAAs by DCs [32, 33]. Moreover, the release of high mobility group protein 1 (HMGB1) from the nucleus is also an indicator of ICD and can facilitate the maturation of DCs by activating TLR4 $[34,35]$. The expression of CALR and HMGB1 in tumor cells after the different treatments was analyzed by IF. As shown in Fig. 3a, not only significantly upregulated CALR expression on the cell surface but also increased HMGB1 release from the cell nucleus could be observed in tumor cells stimulated by DOX or ${ }^{\text {DDP }} \mathrm{NP}_{\text {DOX\&R848. These results indicate }}$ that DOX and ${ }^{\text {DDP }} \mathrm{NP}_{\text {DOX\&R848 }}$ perform well in inducing ICD.

\section{Immunosuppressive cell reversion in vitro.}

To demonstrate the efficacy of ${ }^{D D P} \mathrm{NP}_{\text {DOX\&R848 }}$ in altering the immunosuppressive TME, the R848-loaded component of ${ }^{D D P} \mathrm{NP}_{\text {DOX\&R848 }}$ was used to test the ability of ${ }^{D D P} \mathrm{NP}_{\text {DOX\&R848 }}$ to promote $\mathrm{DC}$ maturation and TAM reeducation in vitro by FCM. DC maturation is a precondition of TAA presentation that initiates the immune response. Bone marrow-derived dendritic cells (BMDCs) were used for the $\mathrm{DC}$ maturation experiment in this study. mDCs are characterized by the upregulated coexpression of CD11c and CD86 and increased secretion of IL-6 and TNF-a. As shown in Fig. 3b, after $24 \mathrm{~h}$ of stimulation by R848 or $\mathrm{NP}_{\mathrm{R} 848}$, the percentage of cells coexpressing CD11c and CD86 (66.7\% and $57.5 \%$, respectively) was significantly higher than that of the PBS-treated group (14.2\%). Additionally, the significantly increased

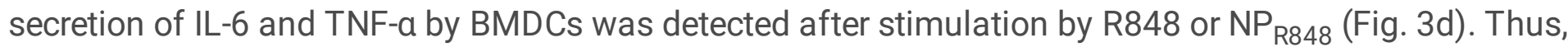
both $\mathrm{R} 848$ and $\mathrm{NP}_{\mathrm{R} 848}$ can effectively mature DCs in vitro. TAMs have been demonstrated to have a close relationship to tumor metastasis and therapeutic resistance and can be identified as one of two phenotypes with distinct functions: tumoricidal (M1 macrophages) or tumorsupportive (M2 macrophages) [36]. TAM reeducation is intended to reverse the high M2 macrophage proportion in the TME. Bone-marrow-derived macrophage cells (BMDMs) were induced to differentiate into M2 macrophages ( $F 4 / 80+C D 206+)$ for the macrophage reeducation experiment. As shown in Fig. 3c, the percentage of M2 macrophages in total macrophages ( $\mathrm{F} 4 / 80+$ ) was $89.5 \%$ in the control group treated with PBS, while this percentage was significantly reduced to $20.3 \%$ and $23.9 \%$ after stimulation by R848 
or $\mathrm{NP}_{\mathrm{R} 848}$, respectively. Additionally, the expression of two proinflammatory cytokines (IL-6 and TNF-a) was reported to be significantly upregulated in M1 macrophages. Thus, the levels of IL- 6 and TNF- $a$ secreted by M2 macrophages treated with R848 or $\mathrm{NP}_{\mathrm{R} 848}$ were both detected (Fig. 3e). Therefore, the ability of $\mathrm{NP}_{\mathrm{R} 848}$ to re-educate TAMs in vitro has also been proven. Therefore, based on valid TME remodeling, ${ }^{\mathrm{DDP}} \mathrm{NP}_{\mathrm{DOX} \& 848}$ is anticipated to induce tumor inhibition.

\section{Biodistribution in vivo.}

To evaluate the superior properties of ${ }^{\mathrm{DDP}} \mathrm{NP}_{\mathrm{DOX} \& \mathrm{R} 848}$ in tumor-targeted accumulation, the in vivo biodistribution of ${ }^{\mathrm{DDP}} \mathrm{NP}_{\mathrm{DOX} \& \mathrm{R} 848}$ after administration was evaluated in an orthotopic osteosarcoma model. Because DOX is a fluorescent drug, IVIS imaging was used to monitor the drug fluorescence intensity of DDP ${ }^{N P_{\text {DOX\&R848 }}}$ (Figure S1). The DOX fluorescence intensity at the tumor site in the ${ }^{D D P}{ }_{N P}$ DOX\&R848 group was about 3.8 times higher than that in the DOX group $12 \mathrm{~h}$ after injection, respectively. This finding demonstrated the outstanding ability of ${ }^{D D P} \mathrm{NP}_{\text {DOX\&R848 }}$ to accumulate in the targeted tumor, which is of vital significance for reducing side effects and improving therapeutic efficacy. Furthermore, the biodistribution of ${ }^{D D P} \mathrm{NP}_{\text {DOX\&R848 }}$ in vivo was also evaluated by measure the amount of DOX in major organs after administration. As shown in Figure $\mathrm{S}_{2},{ }^{\mathrm{DDP}} \mathrm{NP}_{\mathrm{DOX} \& \mathrm{R} 848}$ had a significant tumor site accumulation of $4.0 \pm 0.7 \% \mathrm{ID} \mathrm{g}^{-1} 24 \mathrm{~h}$ after the injection, which is 3.8 times higher than that of DOX. The increased tumor accumulation signifies a high drug concentration in site and tumor inhibition efficiency. In contrast, the uptake of ${ }^{D D P} \mathrm{NP}_{\text {DOX\&R848 }}$ by the liver and kidney was less than that of DOX. This could be attributed to the decreased clearance rate of ${ }^{D D P} \mathrm{NP}_{\text {DOX\&R848 }}$ and was conducive to reduce the side effects. The great feature of prolonged circular time prolongation and tumor-targeting accumulation make ${ }^{\mathrm{DDP}} \mathrm{NP}_{\mathrm{DOX} \& \mathrm{R} 848}$ a potential nanocarrier for in vivo applications.

\section{Antitumor effect in vivo.}

The in vivo antitumor effect of ${ }^{\mathrm{DDP}} \mathrm{NP}_{\mathrm{DOX} \& \mathrm{R} 848}$ was evaluated in a $\mathrm{K} 7 \mathrm{M} 2$ tibiofibular osteosarcoma mouse model (Fig. 4a). As shown in Fig. 4b, the tumors in the control group (PBS-treated) grew robustly, and the average tumor volume reached $787 \pm 58 \mathrm{~mm}^{3}$ by the end of the treatment period. Tumor growth was inhibited to different degrees with the administration of different drugs. The ${ }^{D D P}{ }_{N P} P_{\text {DOx\&R848 }}$-treated group showed the highest tumor regression efficacy, with $154 \pm 60 \mathrm{~mm}^{3}$ as the average tumor volume after all treatments. The order of antitumor efficacy was ${ }^{\mathrm{DDP}} \mathrm{NP}_{\mathrm{D} 0 \mathrm{x} \& \mathrm{R} 848}>\mathrm{NP}_{\mathrm{R} 848}>\mathrm{DDP}+\mathrm{DOX}+\mathrm{R} 848>\mathrm{DDP}_{\mathrm{NP}} \mathrm{DOX}_{\mathrm{D}}$ $>$ R848 > DDP + DOX. To evaluate the therapeutic effect of each treatment more intuitively, the tumor inhibition rate (TIR) and average tumor weight of each group were calculated. As shown in Fig. 4g, the TIR in the ${ }^{\text {DDP }}$ NP $_{\text {DOX \& } 848}$-treated group was $80.5 \pm 7.6 \%$, which was significantly higher than that in the other treatment groups $(P<0.001)$. Then, immunohistochemical staining (TUNEL) were also used to assess the improved antitumor effect of ${ }^{D D P} \mathrm{NP}_{\text {DOX\&R848. }}$. As shown in Figure S3a, the most positive signal was observed in the ${ }^{\text {DDP }} \mathrm{NP}_{\text {DOX\&R848 }}$-treated group. The fluorescence intensity of TUNEL (Figure S3b) in 


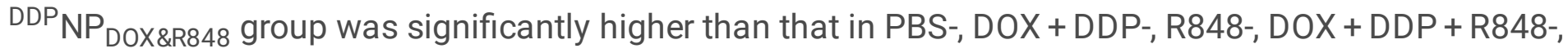
$\mathrm{NP}_{\mathrm{R848}}{ }^{-}$, and ${ }^{\mathrm{DDP}} \mathrm{NP}_{\mathrm{DOX}}$-treated groups $(\mathrm{P}<0.05)$. Compared to other treatments, ${ }^{\mathrm{DDP}} \mathrm{NP}_{\mathrm{DOX} \& \mathrm{R} 848}$ induced the highest degree of tumor cell apoptosis. The lightest tumor weight was also detected in mice treated with ${ }^{\text {DDP }} \mathrm{NP}_{\text {DOX\&R848 }}$ (Fig. S4a). These results clearly show that ${ }^{\text {DDP }} \mathrm{NP}_{\text {DOX\&R848 }}$ exhibits the most robust tumor growth inhibition effect. The security of ${ }^{D D P} \mathrm{NP}_{\text {DOX\&R848 }}$ was evaluated by body weight recording and histology changes observation of four major organs (heart, liver, spleen, kidney). As shown in Fig. 4c, there is no obviously body weight loss could be detected in ${ }^{D D P} \mathrm{NP}_{\mathrm{DOX} \& \mathrm{R} 848}$ group. On the contrary, the mice in free drugs treated group (DOX + DDP, R848, and DOX + DDP + R848) were all observed a significant body weight loss compared to the control group $(P<0.001)$. The histology changes of organs were analyzed by H\&E staining (Figure S5). Consistent with the result of body weight changes, some obvious histology damage, such as ballooming degeneration of liver cell, myofibril degradation, or glomerulus degradation could be found in the group treated with DOX + DDP, R848, or DOX + DDP + R848. However, in the groups treated with drug-loaded nanocarriers ( ${ }^{\mathrm{DDP}} \mathrm{NP}_{\mathrm{DOX}}, \mathrm{NP}_{\mathrm{R} 848}$, and ${ }^{\mathrm{DDP}_{\mathrm{NP}}} \mathrm{DOX}_{\mathrm{DR848}}$ ), no obviously organ damage or only slightly organ damage could be observed. These results demonstrate ${ }^{D D P} N_{\text {DOX\&R848 }}$ could effectively reduce side effects and possess sufficient security compared with free drugs. The survival rate of each group was also recorded (Fig. 4d). Compared with other treatments, ${ }^{D D P} \mathrm{NP}_{\text {DOX\&R848 }}$ displayed the greatest performance in prolonging survival time, which is consistent with its enhanced tumor inhibition efficiency and reduced side effects.

Furthermore, mouse tibiofibular osteosarcomas were also assessed by micro-CT scanning and 3D reconstruction to evaluate bone destruction, which is considered to be positively related to the progression of osteosarcoma [37, 38]. As shown in Fig. 4e, the most serious bone destruction was observed in the PBS-treated group, which was characterized by osteolysis and heterotopic ossification. In contrast, only mild morphological variations in the tibiofibular joint were detected in the ${ }^{\text {DDP }} \mathrm{NP}_{\text {DOX\&R848 }}{ }^{-}$ treated group, and the damage was apparently alleviated compared with that of the other groups. To evaluate bone destruction quality, bone volume/tissue volume (BV/TV) and bone mineral density (BMD) were measured by CTan software. The BV/TV was $56.1 \pm 9.1 \%$ in the ${ }^{\text {DDP }}{ }^{N P_{\text {DOX\&R848 }} \text {-treated group, which }}$ was obviously higher than that in the other groups $(P<0.05)$ (Fig. $4 \mathrm{~h}$ and $\mathrm{i})$. The highest GMD was also found in the ${ }^{D D P} \mathrm{NP}_{\mathrm{DOX} \& \mathrm{R} 848}$-treated group, which was approximately 2.2 times higher than the control group $(\mathrm{P}<0.01) .{ }^{\mathrm{DDP}} \mathrm{NP}_{\mathrm{DOX} \& \mathrm{R} 848}$ was the most robust agent with superior abilities in not only inhibiting osteosarcoma but also preventing bone destruction.

Moreover, the lung is the most common location of osteosarcoma metastases, and it is an influential factor that leads to unsatisfactory outcomes [39]. H\&E staining of the lungs in each group was performed to assess lung metastases. As shown in Fig. 4f, in the PBS-treated group, the most serious lung metastases could be observed. After different treatments, lung metastases could be inhibited to some degree. Surprisingly, no significant lung metastases were detected in the ${ }^{\mathrm{DDP}} \mathrm{NP}_{\mathrm{DOX} \& \mathrm{R} 848}$-treated group. 
Thus, ${ }^{\text {DDP }}$ NP $_{\text {DOX\&R848 }}$ not only demonstrated the highest tumor inhibition efficacy, longest survival time, and least bone destruction but also the greatest performance on lung metastasis resistance.

\section{Immune response.}

After assessing the therapeutic effect, it is clear that ${ }^{\mathrm{DDP}} \mathrm{NP}_{\mathrm{DOX} \& \mathrm{R} 848}$ might exhibit the most robust tumorinhibitory effects. However, whether this antitumor effect contributed to activation of the immune response still requires further study.

First, we tested the effect of ${ }^{D D P} \mathrm{NP}_{\text {DOX\&R848 }}$ on DC maturation. As shown in Fig. 5 a, in the ${ }^{\text {DDP }}{ }_{\text {NP }}$ DOX\&R848 group, the signal of CD86 is obviously stronger than that in other groups. The fluorescence intensity of CD86 in ${ }^{\text {DDP }}$ NP $_{\text {DOX\&R848 }}$ group was about 32 times higher than control group (Fig. 5b), which means ${ }^{D D P}{ }_{N P} P_{\text {DOX \&R848 }}$ could effectively mature DCs in TME. The polarization of TAMs has also been measured by IF. Obviously, as shown in Fig. 5a and c, the highest inducible nitric oxide synthase (iNOS) expression has been observed in the ${ }^{\text {DDP }}$ NP $_{\text {DOX\&R848 }}$ group, which indicated that TAMs in tumors could be effectively reestablished to M1-prevailing TAMs by ${ }^{D D P}{ }^{N} P_{\text {DOX\&R848. }}$. Furthermore, the secretion levels of two important immune-promoting cytokine (IFN-y and IL-6) in tumor have also been qualified (Figure S6). Comparing to the other treatments, ${ }^{D D P}{ }_{N P}{ }_{\text {DOX\&R848 }}$ induced the highest secretion levels of IFN-y and IL- 6 $(\mathrm{P}<0.05) .{ }^{\mathrm{DDP}} \mathrm{NP}_{\mathrm{DOX} \& \mathrm{R} 848}$ showed great potential for TME changeover in vivo, which facilitated activation of the antitumor immune response. It can be concluded that, compared with the other treatments, ${ }^{D D P} \mathrm{NP}_{\text {DOX\&R848 }}$ demonstrated a significantly enhanced effect on DC maturation and TAM polarization.

The proliferation and recruitment of CD8 $+T$ cells in the tumor site was also analyzed by IF to directly evaluate immune activation. As shown in Fig. 5a, an obviously increased signal of CD $8+T$ cells was detected in the ${ }^{\mathrm{DDP}} \mathrm{NP}_{\mathrm{DOX} \& \mathrm{R} 848}$ group. The immunofluorescence images were semiquantitatively analyzed, and the CD8 signals in the ${ }^{{ }^{D P P}} \mathrm{NP}_{\mathrm{DOX} \& \mathrm{R} 848}$-treated group were 16.9, 8.1, 4.4, 3.3, 3.0, and 2.1 times higher than those in the PBS, DOX + DDP, R848, DOX + DDP + R848, ${ }^{D D P} N P_{D 0 X}$, and $\mathrm{NP}_{\mathrm{R} 848}$ groups, respectively (Fig. 5d). Clearly, ${ }^{\text {DDP }} \mathrm{NP}_{\text {DOX\&R848 }}$ induced the most powerful immune response after administration, and the activated immune system played an essential role in eliciting a promising antitumor effect.

\section{Long-term immune memory effect.}

Antigen-specific immune memory is one of the distinct superiorities of tumor immunotherapy [40, 41]. To investigate whether the administration of ${ }^{D D P} \mathrm{NP}_{\mathrm{DOX} \& \mathrm{R} 848}$ could induce effective immune memory, we performed an immune memory evocation experiment (Fig. 6a). The first inoculation of K7M2 cells and the subsequent drug administration were intended to induce primary immunization in vivo. As shown in

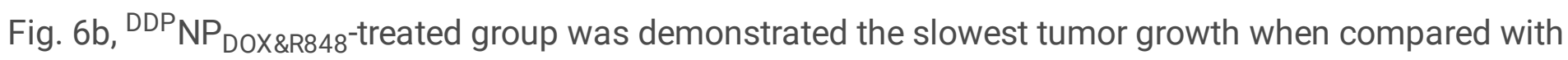
the groups treated with PBS, ${ }^{D D P} \mathrm{NP}_{\mathrm{DOX}}$, and $\mathrm{NP}_{\mathrm{R} 848}$. As shown in Fig. S4bf, the average tumor weight in

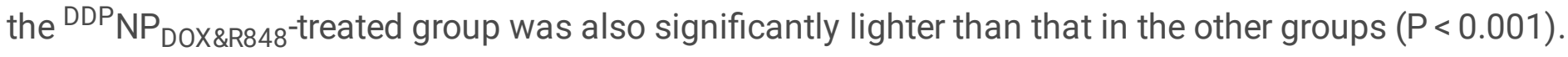


Lung metastasis in the ${ }^{\mathrm{DDP}} \mathrm{NP}_{\mathrm{DOX} \& \mathrm{R} 848}$-treated group has also been restrained effectively compared with groups of the other treatments (Fig. 6d). Furthermore, the strongest immunofluorescence intensity of CD8 was also observed in tumor tissues of mice with ${ }^{\text {DDP }}{ }^{N P_{\text {DOX\&R848 }}}$ administration. (Fig. 6e). This excellent anti-tumor efficiency is consistent with the excellent tumor inhibition efficiency and effective immune activation ability of ${ }^{\text {DDP }} \mathrm{NP}_{\text {DOX\&R848 }}$ in K7M2 tibiofibular osteosarcoma mouse model. Then, we analysed the ability of ${ }^{D D P} N P_{D O X \& R 848}$ to evoke immune memory by effector memory $T\left(T_{E M}\right)$ cells quantification [42]. As shown in Fig. 6f, compared to $\mathrm{NP}_{\mathrm{R} 848},{ }^{\mathrm{DDP}} \mathrm{NP}_{\mathrm{DOX}}$, or PBS, ${ }^{\mathrm{DDP}} \mathrm{NP}_{\mathrm{DOX} \& \mathrm{R} 848}$ exhibited a significantly enhanced ability for $\mathrm{T}_{\mathrm{EM}}$ cell formation in spleen. This means that ${ }^{\mathrm{DDP}} \mathrm{NP}_{\mathrm{DOX} \& \mathrm{R} 848}$ could effectively induce the immune memory response in vivo. Moreover, whether the well-established tumor-specific immune memory could help the mice resist the secondary tumor invasion or not was verified by the following tumor rechallenged experiment. As shown in Fig. 6g, the rechallenged tumor in control group grew at a high rate. However, the tumor growth of mice in ${ }^{\mathrm{DDP}} \mathrm{NP}_{\mathrm{DOX} \& \mathrm{R} 848}$-treated group has been retarded effectively. Three mice in ${ }^{D D P} \mathrm{NP}_{\mathrm{DOX} \& \mathrm{R} 848}$-treated group were observed resist the secondary tumor challenge completely and no sign of tumors could be detected at the rechallenged site. Compared with other treatments, ${ }^{D D P}{ }^{N} P_{\text {DOX\&R848 }}$ has been demonstrated the best performance on the secondary tumor resistance. Additionally, within the observation period, the primary tumor recurrence ratio of mice in ${ }^{D D P} N_{\text {DOX\&R848 }}$ group was obviously reduced when comparing with groups with other treatments (Fig. 6c). Thus, it can be concluded that ${ }^{D D P}{ }_{N P} P_{\text {DOX\&R848 }}$ could activate the immunoreaction effectively and induce valid, tumor-specific immune memory.

\section{Conclusions}

In summary, we have successfully engineered a pH-sensitive nanocarrier for the effective loading and accurate tumor-targeted delivery of DOX, DDP, and R848 in osteosarcoma immunochemotherapy. ${ }^{\mathrm{DDP}} \mathrm{NP}_{\mathrm{DOX} \& \mathrm{R} 848}$ exhibited uniform size, effective drug loading, sufficient stability, and specific $\mathrm{pH}$ dependent drug release. Moreover, the potency of ${ }^{D D P} \mathrm{NP}_{\text {DOX\&R848 }}$ in inducing ICD and immune cell reeducation was also well demonstrated in vitro. Additionally, the outstanding tumor-targeting accumulation made ${ }^{\mathrm{DDP}} \mathrm{NP}_{\mathrm{DOX} \& \mathrm{R} 848}$ a viable candidate for in vivo treatment. The antitumor effect of ${ }^{D D P} \mathrm{NP}_{\text {DOX\&R848 }}$ in vivo was tested using an orthotopic osteosarcoma mouse model, and satisfactory results were observed not only in suppressing tumors but also in stimulating the immune response. Moreover, due to the well-established tumor-specific immune memory by ${ }^{\text {DDP }} \mathrm{NP}_{\text {DOX\&R848, }}$, the rechallenged tumors were also obviously inhibited. Therefore, this work has demonstrated the robust effect of ${ }^{\mathrm{DDP}} \mathrm{NP}_{\mathrm{DOX} \& \mathrm{R} 848}$ in osteosarcoma immunochemotherapy by integrating in situ tumor cell apoptosis and altering the immunosuppression TME. These findings may open a new approach for osteosarcoma treatment in the clinic.

\section{Material And Methods}




\section{Reagents and antibodies}

Low molecular weight sodium hyaluronate (1-10 kDa) was purchased from Bloomage Freda Biopharm Co Ltd. (Shandong, China). Doxorubicin hydrochloride (DOX·HCl), poly-L-histidine, cisplatin, and resiquimod was purchased from was purchased from Sigma-Aldrich (MO, USA). Dulbecco's modified Eagle's medium (DMEM), RPMI-1640 and fetal bovine serum (FBS) were bought from Gibco (NY, USA). All the other solvents and reagents were sourced from Sigma-Aldrich and used as received (MO, USA). Recombinant murine GM-CSF, recombinant murine M-CSF, and recombinant murine IL-4 were purchased from Peprotech (NJ, USA). APC-conjugated antimouse CD11c, PE-conjugated antimouse CD86, PEconjugated antimouse F4/80, APC-conjugated antimouse CD206 were purchased from eBioscience (CA, USA). FITC-conjugated antimouse CD3, APC-conjugated antimouse CD8a, PE-conjugated antimouse CD44, PerCP Cy5.5-conjugated antimouse CD62L were purchased from BioLegend (CA, USA). AntiHMGB1 antibody, anti-CALR antibody, anti-CD86 antibody, anti-iNOS antibody, anti-CD8 antibody, and 4',6diamidino-2-phenylindole (DAPI) were purchased from Abcam (MA, USA).

\section{Preparation Of Np}

$\mathrm{NP}_{\mathrm{R} 848}$ was first prepared by a nanoprecipitation method. Briefly, $20 \mathrm{mg}$ pHis was dissolved in $100 \mu \mathrm{L}$ methanol, and $8 \mathrm{mg} \mathrm{R} 848$ was dissolved in $40 \mu \mathrm{L}$ methanol. Then, the two solutions were mixed and added to $10 \mathrm{~mL}$ borax buffer with a pH of 8.8 to obtain a slightly milky solution. This solution was sonicated using a probe sonicator for $3 \mathrm{~min}$ in an ice bath to obtain $\mathrm{NP}_{\mathrm{R} 848}$. Afterwards, ultrafiltration was used to remove the unloaded R848. High-performance liquid chromatography (HPLC) was used to detect the drug loading content (DLC) of R848 in $\mathrm{NP}_{\mathrm{R} 848}$. Low molecular weight sodium hyaluronate $(200.0 \mathrm{mg})$ lyophilized powder was dissolved in $30.0 \mathrm{~mL}$ of purified deionized water. Then, $4.0 \mathrm{~mL}$ of aqueous DOX hydrochloride solution $(15.0 \mathrm{mg}$ ) was slowly added to the HA solution. The reaction solution was stirred $(800 \mathrm{rpm})$ in the dark at room temperature for $12 \mathrm{~h}$. Then, the solution was dialyzed to remove the free drugs. Purified deionized water was replaced every $2 \mathrm{~h}$ for $24 \mathrm{~h}$. Then, $100 \mathrm{mg} \mathrm{NP} \mathrm{R}_{848}$ was redispersed in deionized water $(\mathrm{pH} \mathrm{7.4)}$ and added dropwise into the solution above. After stirring for $2 \mathrm{~h}$ in darkness, a certain amount of DDP was added to the mixture, and the reaction was continued for $72 \mathrm{~h}$ at $37{ }^{\circ} \mathrm{C}$ to obtain ${ }^{\text {DDP }} \mathrm{NP}_{\text {DOX\&R848. }}$. The molar ratio of $[\mathrm{COOH}] /[\mathrm{DDP}]$ was 50:1. The DLCs of DOX, DDP and R848 were detected by UV-Vis spectrometry, ICP-MS and HPLC, respectively.

ICD inducing in vitro

K7M2 osteosarcoma cells were seeded in 6-well plates at a density of $10^{5}$ cells/well and cultured for $12 \mathrm{~h}$. Then, the original medium was replaced with DMEM containing DOX or ${ }^{\text {DDP }} \mathrm{NP}_{\text {DOX\&R848 }}$ at the same DOX concentration of $2 \mu \mathrm{g} \cdot \mathrm{mL}^{-1}$. After $12 \mathrm{~h}$ incubation, the supernatants were discarded, and the cells were washed with PBS 3 times for subsequent immunofluorescence analyses of HMGB1 and CALR. 
BMDCs and BMDMs were prepared as previously described [43-45]. Briefly, bone marrow cells collected from marrow cavities of tibias of C57BL/ 6 mice (6-8 weeks) were cultured in culture dishes containing $10 \mathrm{~mL}$ RPMI 1640 medium containing streptomycin $\left(100 \mathrm{mg} \mathrm{mL}^{-1}\right)$, penicillin $\left(100 \mathrm{IU} \cdot \mathrm{mL}^{-1}\right)$, and $10 \%$ fetal bovine serum (FBS). For BMDCs generation, GM-CSF $\left(20 \mathrm{ng} \mathrm{mL}^{-1}\right)$ and 2-mercaptoethanol (50 $\left.\mu \mathrm{M}\right)$ were added to the culture medium. On day 3 , another $10 \mathrm{ml}$ culture medium containing GM-CSF and 2mercaptoethanol was added. On days 6 and 8 , half of the culture supernatant was collected and centrifuged, and the cell pellet was resuspended in $10 \mathrm{ml}$ of fresh culture medium containing GM-CSF and 2-mercaptoethanol. On day 10, the nonadherent cells were collected as BMDCs and used in subsequent experiments. BMDMs were generated by incubating bone marrow-derived cells with medium containing M-CSF $\left(20 \mathrm{ng} \mathrm{mL}^{-1}\right)$. On days 3 and 5 , the medium was replaced with fresh M-CSF-containing medium. Adherent cells were harvested on day 7 as BMDMs.

BMDCs were treated with $\mathrm{R} 848$ or $\mathrm{NP}_{\mathrm{R} 848}$ at the same $\mathrm{R} 848$ concentration of $0.1 \mu \mathrm{g} \cdot \mathrm{mL}^{-1}$ for $24 \mathrm{~h}$. Then, cells were collocated for FCM analysis. The levels of IL- 6 and TNF- $a$ in cell supernatants of BMDCs with different stimulated R848 concentrations were analyzed by ELISA. BMDMs were first stimulated with IL-4 (10 $\mathrm{ng} \mathrm{mL}^{-1}$ ) for $24 \mathrm{~h}$ to induce an M2-like state. Then, cells were treated with R848 or $\mathrm{NP}_{\mathrm{R} 848}$ at the same R848 concentration of $0.1 \mu \mathrm{g} \cdot \mathrm{mL}^{-1}$. After $24 \mathrm{~h}$ incubation, cells were collocated for FCM analysis. The levels of IL- 6 and TNF- $a$ in cell supernatants of macrophages with different stimulated R848 concentrations were also detected by ELISA.

\section{Establishment of orthotopic osteosarcoma model}

Female BALB/c mice (6-8 weeks) were purchased from Nanjing Medical University Laboratory Animal Center. All animal experiments were performed in accordance with guidelines approved by the Animal Ethical and Welfare Committee of Nanjing Medical University (IACUC-1903035). For K7M2 orthotopic osteosarcoma mouse model establishment, each $2 \times 10^{6} \mathrm{~K} 7 \mathrm{M} 2$ cells in $20 \mu \mathrm{L}$ PBS solution were injected into the right tibia of the mouse. The volume of osteosarcoma in situ was calculated as in a previous study [46].

\section{In vivo antitumor efficiency}

Orthotopic osteosarcoma models were established as described above to evaluate the in vivo antitumor efficacy. When all the tumors grew to approximately $65 \mathrm{~mm}^{3}$, mice were randomly divided into 7 groups ( $n=8$ for each group). Mice in the treatment groups were treated with PBS, DOX + DDP, R848, DOX + DDP $+\mathrm{R} 848,{ }^{\mathrm{DDP}} \mathrm{NP}_{\mathrm{DOX}}, \mathrm{NP}_{\mathrm{R} 848}$, or ${ }^{\mathrm{DDP}} \mathrm{NP}_{\mathrm{DOX} \& \mathrm{R} 848}$ with an equivalent $\mathrm{R} 848$ dose of $2.0 \mathrm{mg}(\mathrm{kg} \mathrm{BW})^{-1}$ on days $1,5,9,13$ and 17 by intravenous injection. According to the drug loading ratio of drugs in ${ }^{\mathrm{DDP}} \mathrm{NP}_{\text {DOX \& R848, }}$ the treatment DOX dose in different groups is $1.3 \mathrm{mg}\left(\mathrm{kg} \mathrm{BW}^{-1}\right.$. The tumor size and body weight were measured every three days. On the 3rd day after the last drug injection, 3 mice in each group were sacrificed, and the tumors were excised, washed, and precisely weighed. Subsequently, these tissues were analyzed immediately or fixed in 4\% (W/V) PBS-buffered paraformaldehyde for further analyses. Before 
further disposal, the isolated tumors were promptly scanned by Micro-CT (SkyScan 1176 System) to evaluate bone destruction. The image pixel size was set as $35.52 \mu \mathrm{m}$. After data collection, CTvox software was used for 3D reconstruction, and bone parameters were analyzed by CTAn software.

\section{Analysis Of Tme Re-establishment After Treatment}

The re-establishment of TME after different treatments were analysed by IF. The paraffin-embedded tumors were cut into $\sim 3 \mathrm{~mm}$ sheets for immunohistochemical analyses. CD86 and iNOS were used to the marker to display the DCs activation and TAM re-education in tumors, respectively. CD8 was stained to evaluated the cytotoxic T cells proliferation in tumors after different treatments. The histological and immunohistochemical alterations were detected by a microscope and subsequently analyzed with ImageJ software. To determine cytokine concentrations in tumors, the separated tumors were homogenized in a protein extraction buffer containing a protease inhibitor $(1 \mathrm{~mL})$. The cytokine concentrations in the tissues were analyzed by ELISA according to the manufacturer's instructions and determined as $\mathrm{pg} \mathrm{mg}^{-1}$ of protein.

\section{Long-term Immune Memory Effect}

In total, $2 \times 10^{6} \mathrm{~K} 7 \mathrm{M} 2$ cells in $0.1 \mathrm{~mL}$ of PBS were subcutaneously injected into the right flank of each female BALB/c mouse (6-8 weeks) to generate a K7M2 osteosarcoma-allografted mouse model. When the average tumor volume approached $50 \mathrm{~mm}^{3}$, the mice were randomly divided into 4 groups $(n=8)$ and received different treatments at an equivalent $\mathrm{R} 848$ dose of $2.0 \mathrm{mg}\left(\mathrm{kg} \mathrm{BW}^{-1}\right.$ by intravenous injection every four days (PBS, ${ }^{D D P} \mathrm{NP}_{\mathrm{DOX}}, \mathrm{NP}_{\mathrm{R} 848}$, or ${ }^{\mathrm{DDP}} \mathrm{NP}_{\mathrm{DOX} \& \mathrm{R} 848}$ ). According to the drug loading ratio of drugs in ${ }^{\mathrm{DDP}} \mathrm{NP}_{\mathrm{DOX} \& \mathrm{R} 848}$, the treatment DOX dose in different groups is $1.3 \mathrm{mg}(\mathrm{kg} \mathrm{BW})^{-1}$. The tumor size was measured every three days. After 4 times treatments, 3 mice in each group were sacrificed, and the tumors and spleens were excised, washed, and precisely weighed. The CD8 T cells in tumors was tested by IF staining. $T_{E M}$ cells (CD3 + CD 8 + CD44 + CD62L-) in spleen was analyzed by FCM after separating lymphocytes in spleen by mouse lymphocyte separating fluid. The tumors in the remaining 5 mice in each group were surgically resected. Twenty days later, these mice were rechallenged with K7M2 cells in the left flank. The distant tumor size in every group were measured every 3 days.

\section{Statistical Analyses}

Experiments were performed in at least three independent biological replicates. Data were expressed as mean \pm standard deviation. Statistical analysis was performed using GraphPad software 8.0 and SPSS 25.0. A Student's $t$-test for two-group comparisons and one-way or two-way ANOVA for more than twogroup comparisons were used to calculate the P-values. A value of $P<0.05$ was regarded as statistically significant. 


\section{Abbreviations}

BMD

bone mineral density; BMDCs:bone marrow-derived dendritic cells; BSA:bovine serum albumin; BV/TV:bone volume/ tissue volume; CALR:calreticulin; DCs:dendritic cells; DDP:cisplatin; DDS:drug delivery system; Dhs:hydrodynamic diameter; DOX:doxorubicin; FBS:fetal bovine serum; HA:hyaluronic acid; H\&E:hematoxylin-eosin; HMGB1:high mobility group protein 1; HPLC:high performance liquid chromatography; ICD:immunogenic cell death; iNOS:inducible nitric oxide synthase; pHis:poly-L-histidine; R848:resiquimod; ROIs:the regions of interest; TAA:tumor association antigen; TAM:tumor-associated macrophage; TEM:transmission electron microscope; $\mathrm{T}_{\mathrm{EM}}$ : effector memory $T$ cells; TLR:toll-like receptor; TME:tumor microenvironment.

\section{Declarations}

\section{Ethics approval and consent to participate}

All animal procedures were performed under the guidelines of the institutional review board and the ethics committee of Nanjing Medical University (IACUC-1903035).

\section{Consent for publication}

Not applicable

\section{Availability of data and material}

Most of the datasets supporting the conclusions of this article are included within this article and the additional files. The datasets used or analyzed during the current study are available on reasonable request.

\section{Conflict of interest}

The authors declare no conflict of interest.

\section{Acknowledgements}

Not applicable

\section{Funding}

This work was sponsored by the National Natural Science Foundation of China (Grant No. 81672169 , 81974332).

\section{Authors' contributions}


Fan WM designed and supervised this study. Zhang $Y$ and Yuan T conducted the majority of the experiments and completed the manuscript. Zhang Y, Li ZX, and Luo CY analyzed the data. Zhang Y, Wu $Y X$, Zhang JY, and Zhang $X$ participated the experiments and the manuscript writing. Zhang $Y, W u Y X$ and Fan WM participated in editing the manuscript. All authors approved the final version of the manuscript.

Acknowledgements

Not applicable

Author details

The First Affiliated Hospital of Nanjing Medical University, Nanjing, Jiangsu, 210029, China

\section{References}

1. Kansara M, Teng MW, Smyth MJ, Thomas DM: Translational biology of osteosarcoma. Nature reviews Cancer 2014, 14:722-735.

2. Gianferante DM, Mirabello L, Savage SA: Germline and somatic genetics of osteosarcoma connecting aetiology, biology and therapy. Nature reviews Endocrinology 2017, 13:480-491.

3. Mirabello L, Troisi RJ, Savage SA: Osteosarcoma Incidence and Survival Rates From 1973 to 2004 Data From the Surveillance, Epidemiology, and End Results Program. Cancer 2009, 115:1531-1543.

4. Li J, Rao J, Pu K: Recent progress on semiconducting polymer nanoparticles for molecular imaging and cancer phototherapy. Biomaterials 2018, 155:217-235.

5. Patra JK, Das G, Fraceto LF, Ramos Campos EV, del Pilar Rodriguez-Torres M, Susana Acosta-Torres L, Armando Diaz-Torres L, Grillo R, Swamy MK, Sharma S, et al: Nano based drug delivery systems: recent developments and future prospects. Journal of Nanobiotechnology 2018, 16.

6. Rosenblum D, Joshi N, Tao W, Karp JM, Peer D: Progress and challenges towards targeted delivery of cancer therapeutics. Nature Communications 2018, 9.

7. Gai S, Yang G, Yang P, He F, Lin J, Jin D, Xing B: Recent advances in functional nanomaterials for light-triggered cancer therapy. Nano Today 2018, 19:146-187.

8. Ji X, Kong N, Wang J, Li W, Xiao Y, Gan ST, Zhang Y, Li Y, Song X, Xiong Q, et al: A Novel Top-Down Synthesis of Ultrathin 2D Boron Nanosheets for Multimodal Imaging-Guided Cancer Therapy. Advanced Materials 2018, 30.

9. Peng F, Setyawati MI, Tee JK, Ding X, Wang J, Nga ME, Ho HK, Leong DT: Nanoparticles promote in vivo breast cancer cell intravasation and extravasation by inducing endothelial leakiness. Nature Nanotechnology 2019, 14:279-+.

10. Yi Z, Feng W, Mingqiang L, Zhiqiang Y, Ruogu Q, Jianxun D, Zhiyu Z, Xuesi C: Self-Stabilized Hyaluronate Nanogel for Intracellular Codelivery of Doxorubicin and Cisplatin to Osteosarcoma. Advanced Science 2018, 5:1700821. 
11. Pardoll DM: The blockade of immune checkpoints in cancer immunotherapy. Nature Reviews Cancer 2012, 12:252-264.

12. Kroemer G, Zitvogel L: Cancer immunotherapy in 2017: The breakthrough of the microbiota. Nature reviews Immunology 2018, 18:87-88.

13. Martin JD, Cabral H, Stylianopoulos T, Jain RK: Improving cancer immunotherapy using nanomedicines: progress, opportunities and challenges. Nature Reviews Clinical Oncology 2020, 17:251-266.

14. Topalian SL, Taube JM, Pardoll DM: Neoadjuvant checkpoint blockade for cancer immunotherapy. Science 2020, 367:525-+.

15. Chalabi M, Fanchi LF, Dijkstra KK, van den Berg JG, Aalbers AG, Sikorska K, Lopez-Yurda M, Grootscholten C, Beets GL, Snaebjornsson P, et al: Neoadjuvant immunotherapy leads to pathological responses in MMR-proficient and MMR-deficient early-stage colon cancers. Nature Medicine 2020.

16. Hegde PS, Chen DS: Top 10 Challenges in Cancer Immunotherapy. Immunity 2020, 52:17-35.

17. Weber JS, Yang JC, Atkins MB, Disis ML: Toxicities of Immunotherapy for the Practitioner. Journal of clinical oncology : official journal of the American Society of Clinical Oncology 2015, 33:2092-2099.

18. Huang Y, Chen Y, Zhou S, Chen L, Wang J, Pei Y, Xu M, Feng J, Jiang T, Liang K, et al: Dualmechanism based CTLs infiltration enhancement initiated by Nano-sapper potentiates immunotherapy against immuneexcluded tumors. Nature Communications 2020, 11.

19. Liu X, Feng Z, Wang C, Su Q, Song H, Zhang C, Huang P, Liang X-J, Dong A, Kong D, Wang W: Colocalized delivery of nanomedicine and nanovaccine augments the postoperative cancer immunotherapy by amplifying T-cell responses. Biomaterials 2020, 230.

20. Zhang $\mathrm{Y}$, Chen $\mathrm{H}$, Wang H, Wang T, Pan H, Ji W, Chang J: A synergistic cancer immunotherapy nanosystem for preventing tumor growth. Chemical Engineering Journal 2020, 380.

21. Zhang Y, Cai L, Li D, Lao Y-H, Liu D, Li M, Ding J, Chen X: Tumor microenvironment-responsive hyaluronate-calcium carbonate hybrid nanoparticle enables effective chemotherapy for primary and advanced osteosarcomas. Nano Research 2018.

22. McTiernan A, Jinks RC, Sydes MR, Uscinska B, Hook JM, van Glabbeke M, Bramwell V, Lewis IJ, Taminiau AH, Nooij MA, et al: Presence of chemotherapy-induced toxicity predicts improved survival in patients with localised extremity osteosarcoma treated with doxorubicin and cisplatin: a report from the European Osteosarcoma Intergroup. Eur J Cancer 2012, 48:703-712.

23. Ma H, He C, Cheng Y, Yang Z, Zang J, Liu J, Chen X: Localized Co-delivery of Doxorubicin, Cisplatin, and Methotrexate by Thermosensitive Hydrogels for Enhanced Osteosarcoma Treatment. ACS Applied Materials \& Interfaces 2015, 7:27040-27048.

24. Khafaji M, Zamani M, Vossoughi M, Iraji Zad A: Doxorubicin/Cisplatin-Loaded Superparamagnetic Nanoparticles As A Stimuli-Responsive Co-Delivery System For Chemo-Photothermal Therapy. Int J Nanomedicine 2019, 14:8769-8786.

25. Yang W, Zhu G, Wang S, Yu G, Yang Z, Lin L, Zhou Z, Liu Y, Dai Y, Zhang F, et al: In Situ Dendritic Cell Vaccine for Effective Cancer Immunotherapy. ACS nano 2019, 13:3083-3094. 
26. Lim S, Park J, Shim MK, Um W, Yoon HY, Ryu JH, Lim D-K, Kim K: Recent advances and challenges of repurposing nanoparticle-based drug delivery systems to enhance cancer immunotherapy.

Theranostics 2019, 9:7906-7923.

27. Rodell CB, Arlauckas SP, Cuccarese MF, Garris CS, Ahmed RLMS, Kohler RH, Pittet MJ, Weissleder R: TLR7/8-agonist-loaded nanoparticles promote the polarization of tumour-associated macrophages to enhance cancer immunotherapy. Nature Biomedical Engineering 2018, 2:578-+.

28. Song Y, Wang Y, Wang S, Cheng Y, Lu Q, Yang L, Tan F, Li N: Immune-adjuvant loaded Bi2Se3 nanocage for photothermal-improved PD-L1 checkpoint blockade immune-tumor metastasis therapy. Nano Research 2019, 12:1770-1780.

29. Zhang T, Lip H, He C, Cai P, Wang Z, Henderson JT, Rauth AM, Wu XY: Multitargeted Nanoparticles Deliver Synergistic Drugs across the Blood-Brain Barrier to Brain Metastases of Triple Negative Breast Cancer Cells and Tumor-Associated Macrophages. Adv Healthc Mater 2019, 8:e1900543.

30. Nasrollahzadeh E, Razi S, Keshavarz-Fathi M, Mazzone M, Rezaei N: Pro-tumorigenic functions of macrophages at the primary, invasive and metastatic tumor site. Cancer Immunol Immunother 2020, 69:1673-1697.

31. Liu YY, Qiao LN, Zhang SP, Wan GY, Chen BW, Zhou P, Zhang N, Wang YS: Dual pH-responsive multifunctional nanoparticles for targeted treatment of breast cancer by combining immunotherapy and chemotherapy. Acta Biomaterialia 2018, 66:310-324.

32. Liu P, Zhao L, Pol J, Levesque S, Petrazzuolo A, Pfirschke C, Engblom C, Rickelt S, Yamazaki T, Iribarren K, et al: Crizotinib-induced immunogenic cell death in non-small cell lung cancer. Nature communications 2019, 10:1486.

33. Zhang C, Yan L, Gu Z, Zhao Y: Strategies based on metal-based nanoparticles for hypoxic-tumor radiotherapy. Chemical Science 2019, 10:6932-6943.

34. Feng B, Zhou F, Hou B, Wang D, Wang T, Fu Y, Ma Y, Yu H, Li Y: Binary Cooperative Prodrug Nanoparticles Improve Immunotherapy by Synergistically Modulating Immune Tumor Microenvironment. Advanced materials 2018, 30:e1803001.

35. Wang X, Zhong X, Gong F, Chao Y, Cheng L: Newly developed strategies for improving sonodynamic therapy. Materials Horizons 2020, 7:2028-2046.

36. Mantovani A, Marchesi F, Malesci A, Laghi L, Allavena P: Tumour-associated macrophages as treatment targets in oncology. Nature Reviews Clinical Oncology 2017, 14:399-416.

37. Liang C, Li F, Wang L, Zhang Z-K, Wang C, He B, Li J, Chen Z, Shaikh AB, Liu J, et al: Tumor celltargeted delivery of CRISPR/Cas9 by aptamer-functionalized lipopolymer for therapeutic genome editing of VEGFA in osteosarcoma. Biomaterials 2017, 147:68-85.

38. Yang Q, Yin H, Xu T, Zhu D, Yin J, Chen Y, Yu X, Gao J, Zhang C, Chen Y, Gao Y: Engineering 2D Mesoporous Silica@MXene-Integrated 3D-Printing Scaffolds for Combinatory Osteosarcoma Therapy and NO-Augmented Bone Regeneration. Small 2020, 16:1906814.

39. Hu J, Wang F, Liu F, Sun W, Jiang Q, Liu Y, Zhao Y, Liu X: Effective nanotherapeutic approach for metastatic breast cancer treatment by supplemental oxygenation and imaging-guided phototherapy. 
Nano Research 2020, 13:1111-1121.

40. Cabrita R, Lauss M, Sanna A, Donia M, Larsen MS, Mitra S, Johansson I, Phung B, Harbst K, VallonChristersson J, et al: Tertiary lymphoid structures improve immunotherapy and survival in melanoma. Nature 2020, 577:561-+.

41. Strauss L, Mahmoud MAA, Weaver JD, Tijaro-Ovalle NM, Christofides A, Wang Q, Pal R, Yuan M, Asara J, Patsoukis N, Boussiotis VA: Targeted deletion of PD-1 in myeloid cells induces antitumor immunity. Science Immunology 2020, 5.

42. Han X, Wang R, Xu J, Chen Q, Liang C, Chen J, Zhao J, Chu J, Fan Q, Archibong E, et al: In situ thermal ablation of tumors in combination with nano-adjuvant and immune checkpoint blockade to inhibit cancer metastasis and recurrence. Biomaterials 2019, 224:119490.

43. Barry KC, Hsu J, Broz ML, Cueto FJ, Binnewies M, Combes AJ, Nelson AE, Loo K, Kumar R, Rosenblum $\mathrm{MD}$, et al: A natural killer-dendritic cell axis defines checkpoint therapy-responsive tumor microenvironments. Nature medicine 2018, 24:1178-1191.

44. Yang J, Arya S, Lung P, Lin Q, Huang J, Li Q: Hybrid nanovaccine for the co-delivery of the mRNA antigen and adjuvant. Nanoscale 2019, 11:21782-21789.

45. Zhang Y-R, Luo J-Q, Li J-X, Huang Q-Y, Shi X-X, Huang Y-C, Leong KW, He W-I, Du J-Z: Biofunctional Janus particles promote phagocytosis of tumor cells by macrophages. Chemical Science 2020, 11:5323-5327.

46. Li K, Li D, Zhao L, Chang Y, Zhang Y, Cui Y, Zhang Z: Calcium-mineralized polypeptide nanoparticle for intracellular drug delivery in osteosarcoma chemotherapy. Bioactive Materials 2020, 5:721-731.

\section{Figures}
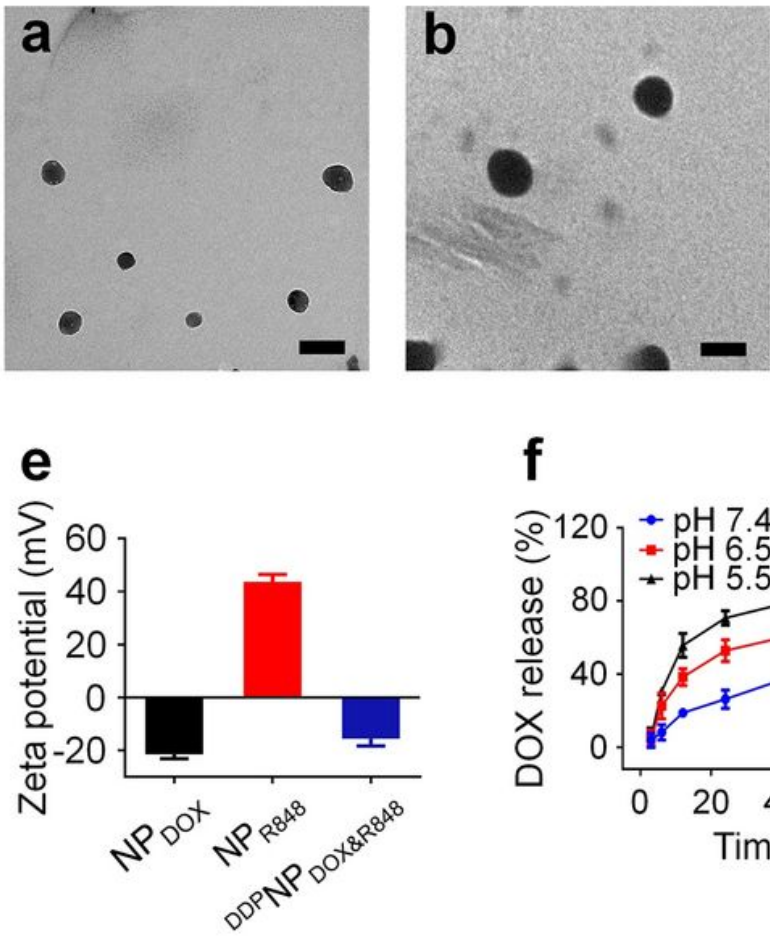
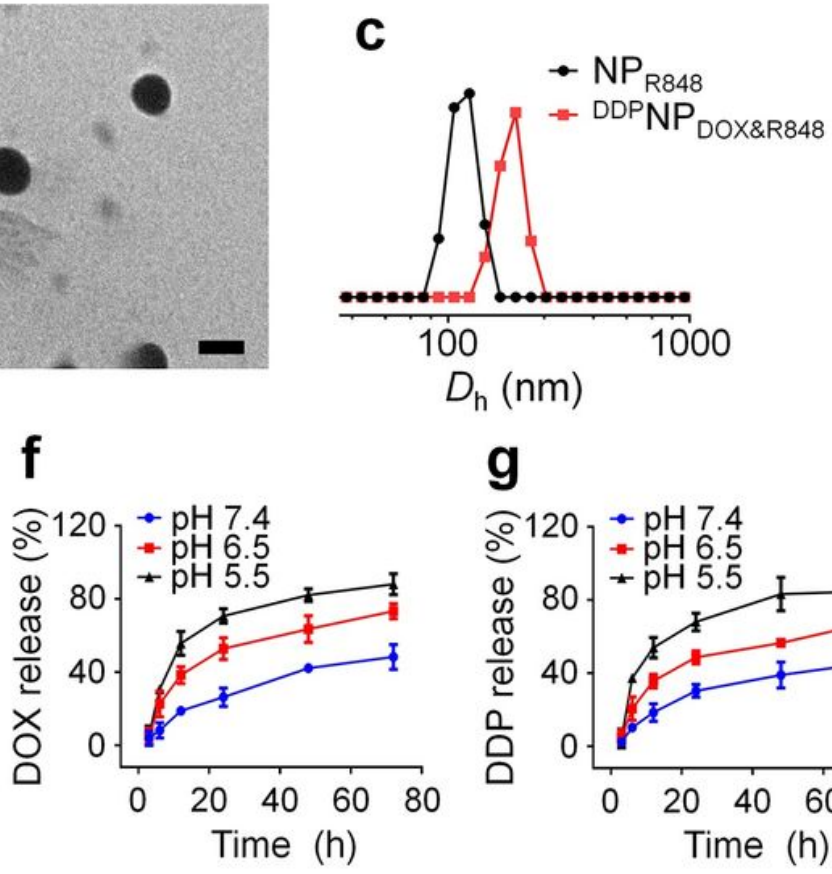

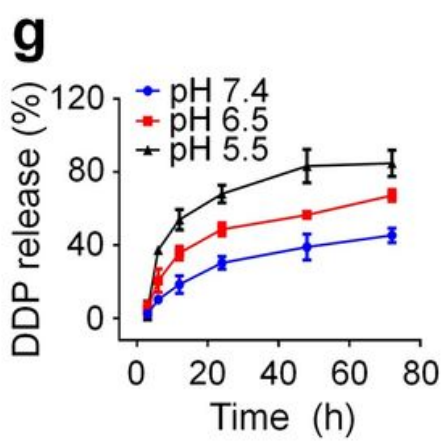

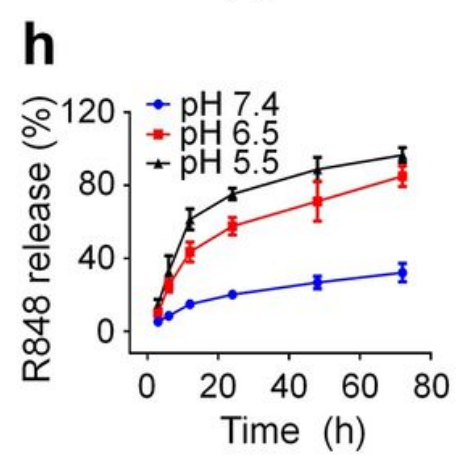

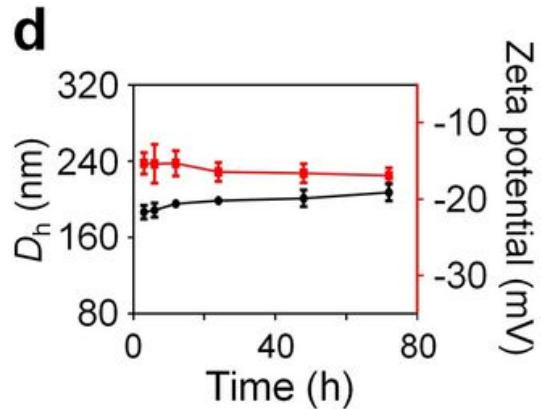


Figure 1

TEM images of a NPR848 and b DDPNPDOX\&R848. Scale bars: $200 \mathrm{~nm}$. c Size distribution of NPR848 and DDPNPDOX\&R848. $\mathrm{d}$ Size and zata potential changes of DDPNPDOX\&R848 in 10\% FBS solution over different times. e Zeta potential of NPDOX, NPR848, and DDPNPDOX\&R848. $\mathrm{f}$ - $\mathrm{h}$ Cumulative drug release from DDPNPDOX\&R848 under different $\mathrm{pH}$ values $(7.4,6.5$, and 5.5$)$.

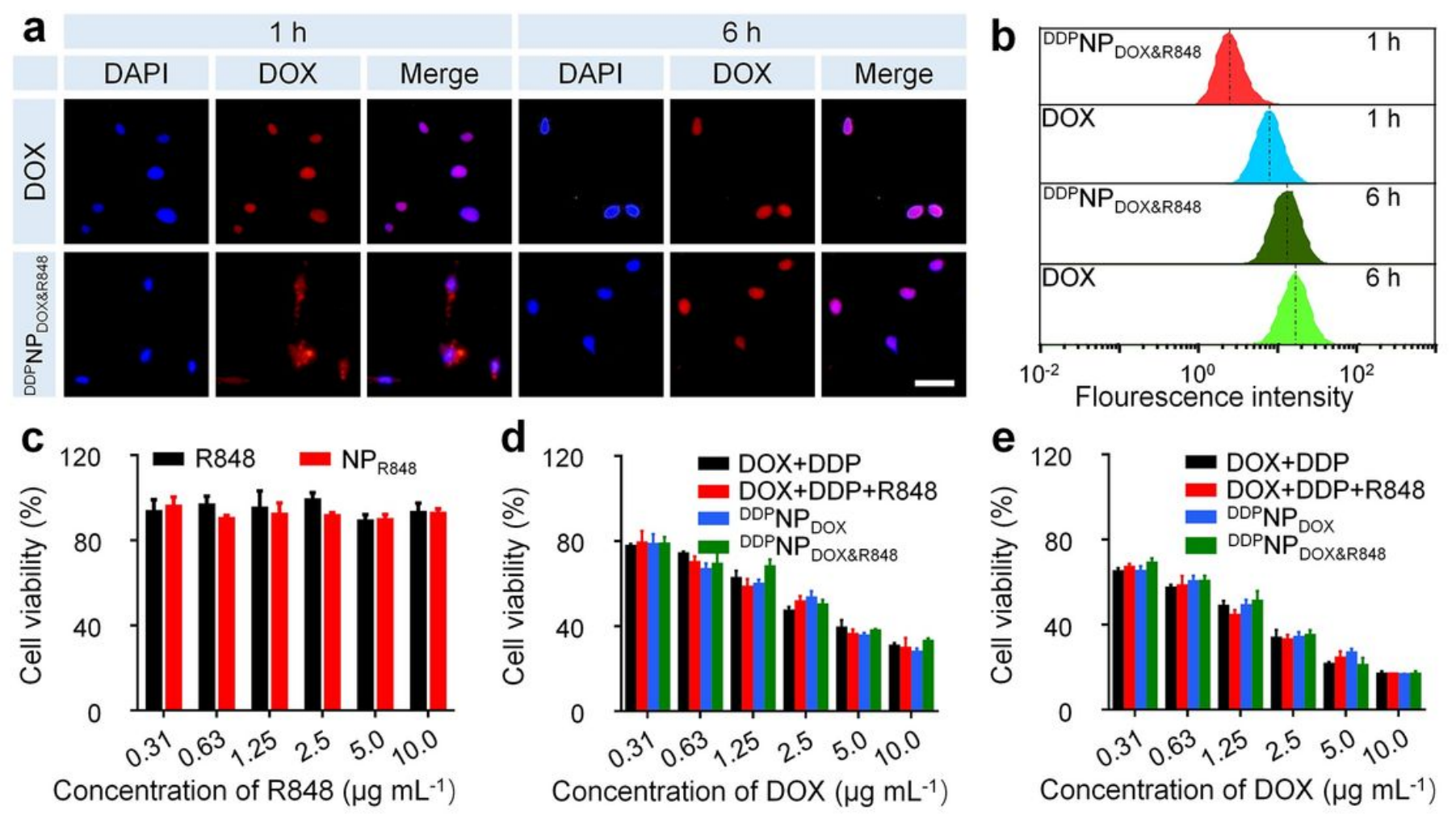

Figure 2

Tumor cell uptake and cytotoxicity a Fluorescence images and b flow cytometry analysis of K7M2 osteosarcoma cells after incubation with DOX or DDPNPDOX\&R848 for 1 and $6 \mathrm{~h}$. Scale bars: $200 \mu \mathrm{m}$. C Cell viability of K7M2 osteosarcoma cells after treatment with R848 or pHis/R848 at various R848 concentrations after $48 \mathrm{~h}$ of incubation. Cell viability of K7M2 osteosarcoma cells after treatment with DOX + DDP, DOX + DDP + R848, DDPNPDOX, or DDPNPDOX\&R848 at various DOX concentrations after d $24 \mathrm{~h}$ and e $48 \mathrm{~h}$, respectively. 

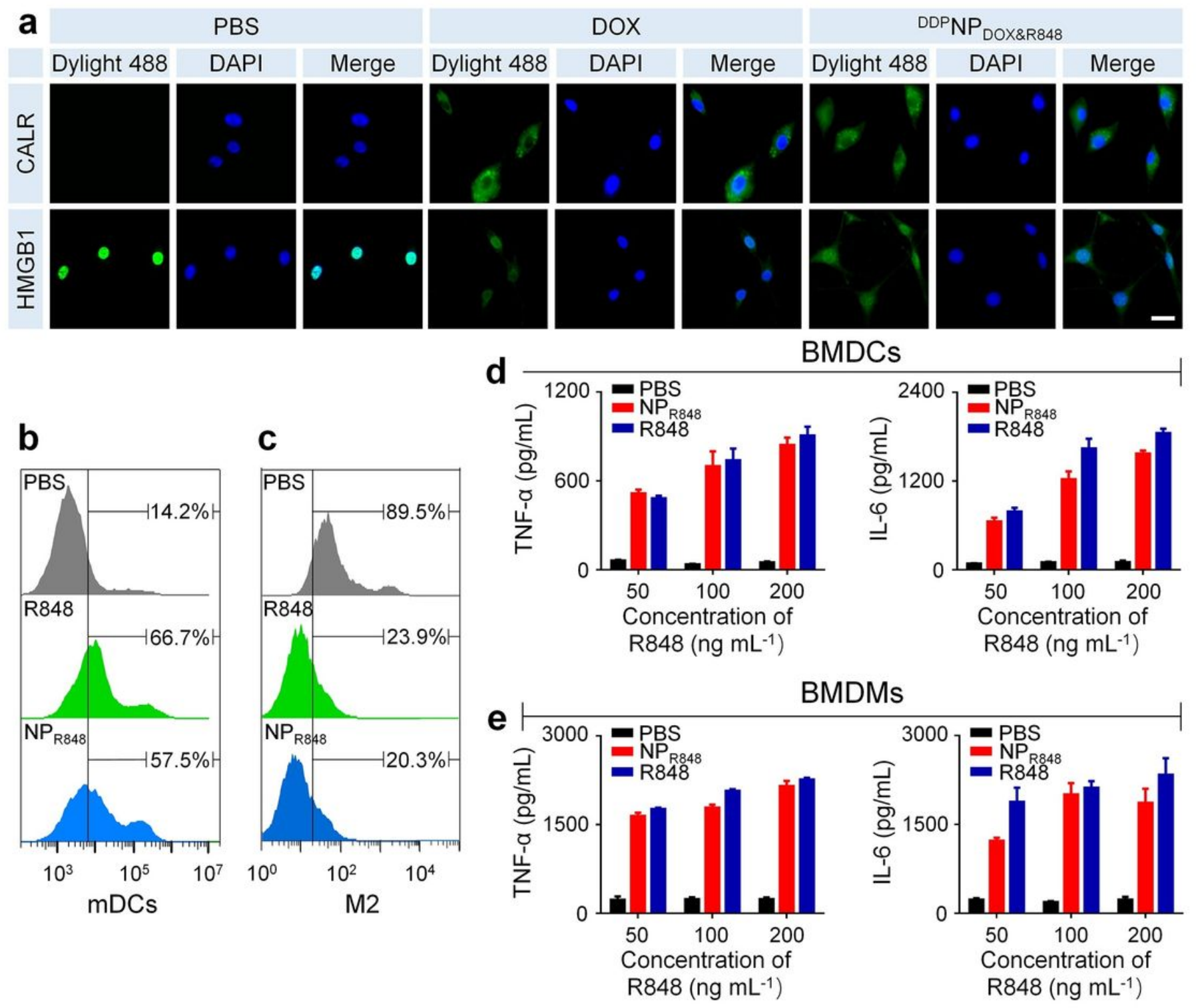

Figure 3

ICD induction and immune cell reeducation a Immunofluorescence of CALR and HMGB1 in K7M2 osteosarcoma cells after incubation with DOX or DDPNPDOX\&R848 for $12 \mathrm{~h}$. Scale bars: $60 \mu \mathrm{m}$. Flow cytometry quantification of b mDCs (CD11c+ CD86+) and c M2 macrophages (F4/80+ CD206+) after incubation of BMDCs or BMDMs with R848 or pHis/R848 for $24 \mathrm{~h}$. The production of proinflammatory cytokines (TNF- $\alpha$ and IL-6) in cell supernatants of $d$ BMDCs and e BMDMs was analyzed by ELISA. 
a
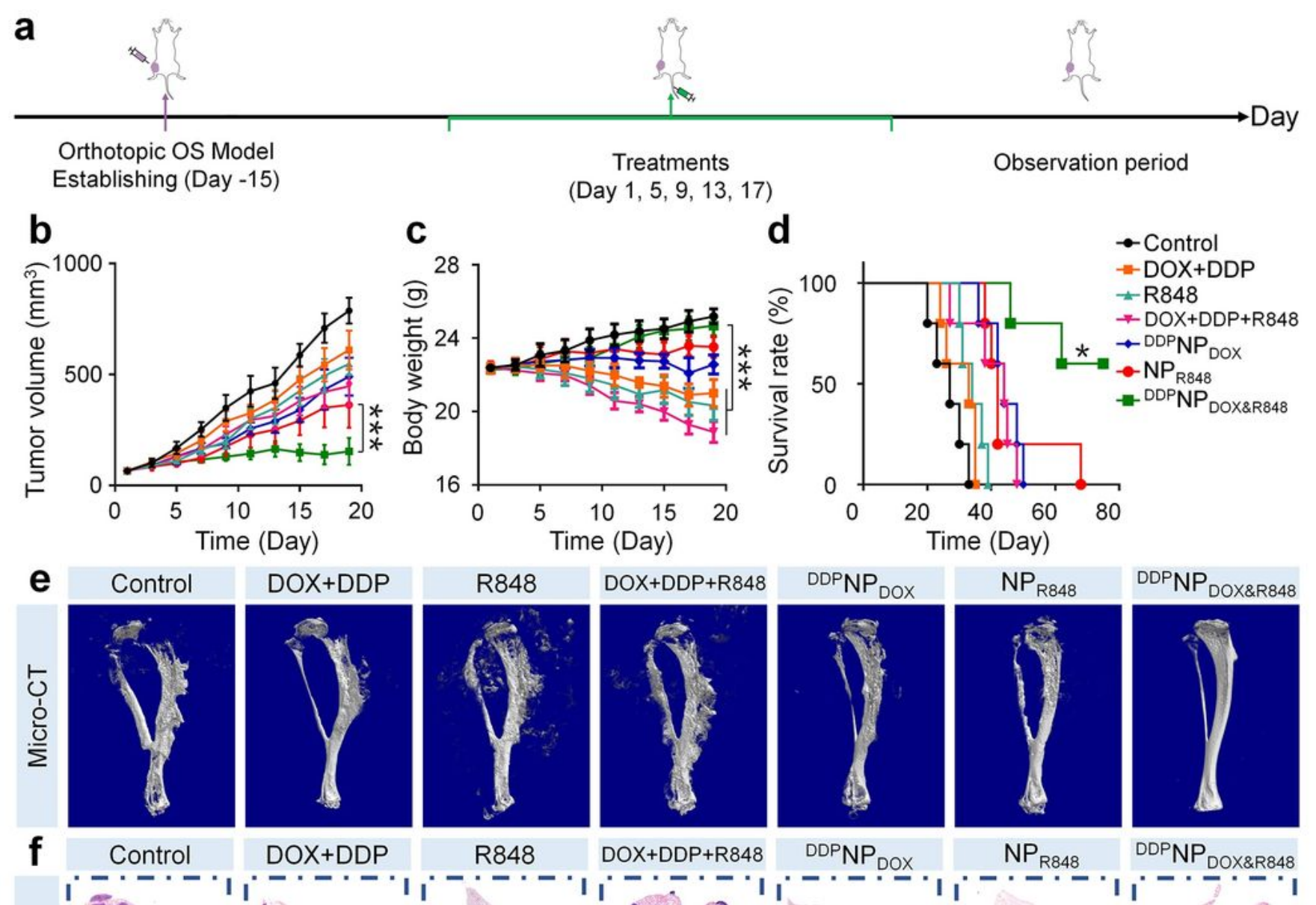

DDPNP DOX

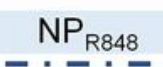

DDPNP ${ }_{\text {DOX\&R848 }}$
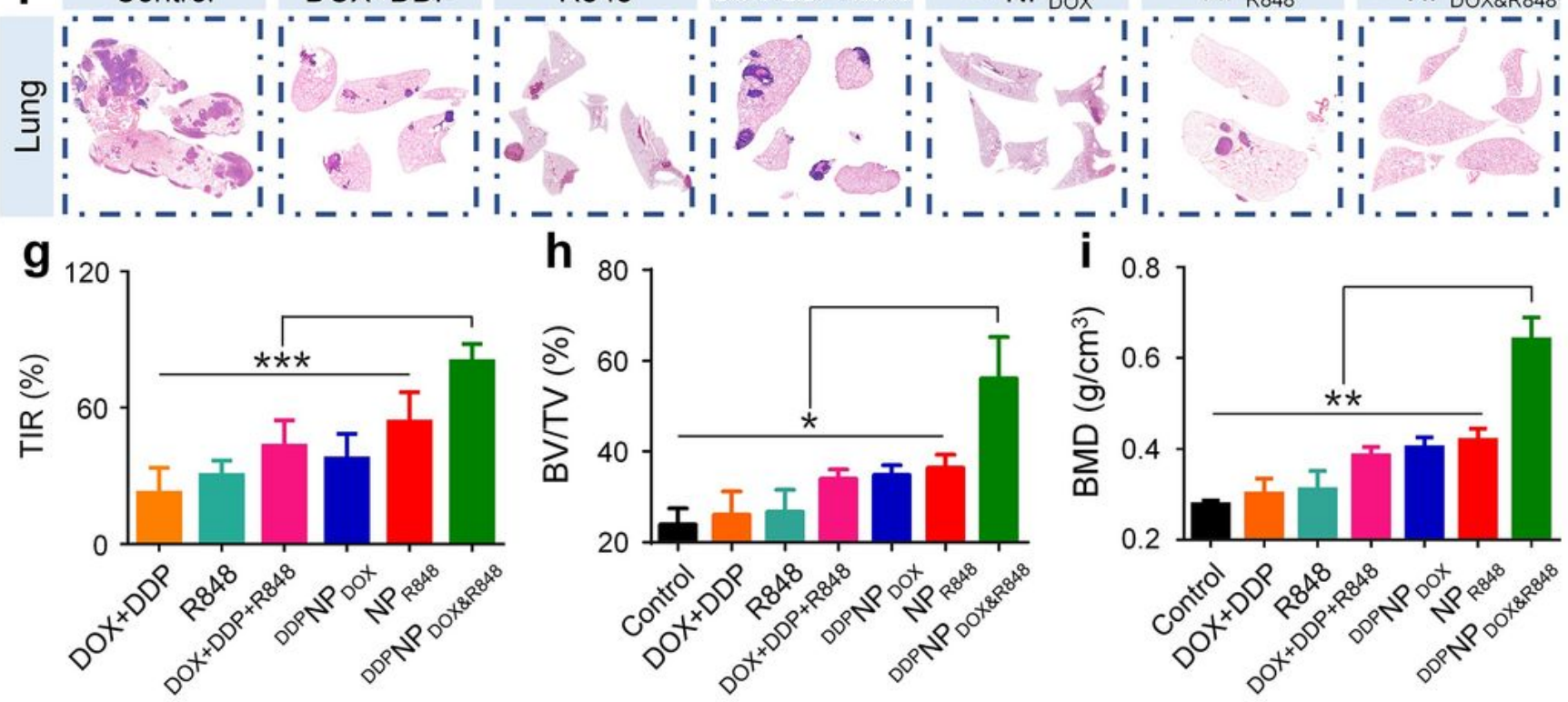

\section{Figure 4}

Antitumor effect in vivo a Experimental schedule for tumor induction and drug treatments. b Tumor volume, $c$ body weight, and d survival rate of mice after various treatments in seven groups. e 3D reconstructed images of the tibia in the orthotopic osteosarcoma inhibition experiment performed using micro-CT and $\mathrm{h} B V / T V$ and $\mathrm{B} B \mathrm{~B}$ in the ROls of the tibia in the orthotopic osteosarcoma inhibition experiment. $\mathrm{f} \mathrm{H \& E}$ staining analysis of lung metastasis in mice in different groups. g TIR of DOX + DDP, 
DOX + DDP + R848, DDPNPDOX, NPR848, and DDPNPDOX\&R848 in this experiment. Data are presented as the mean \pm SD $(n=8$ for $b-d$ and $g ; n=3$ for $h-i ; * P<0.05$, ** $P<0.01$, *** $P<0.001)$.

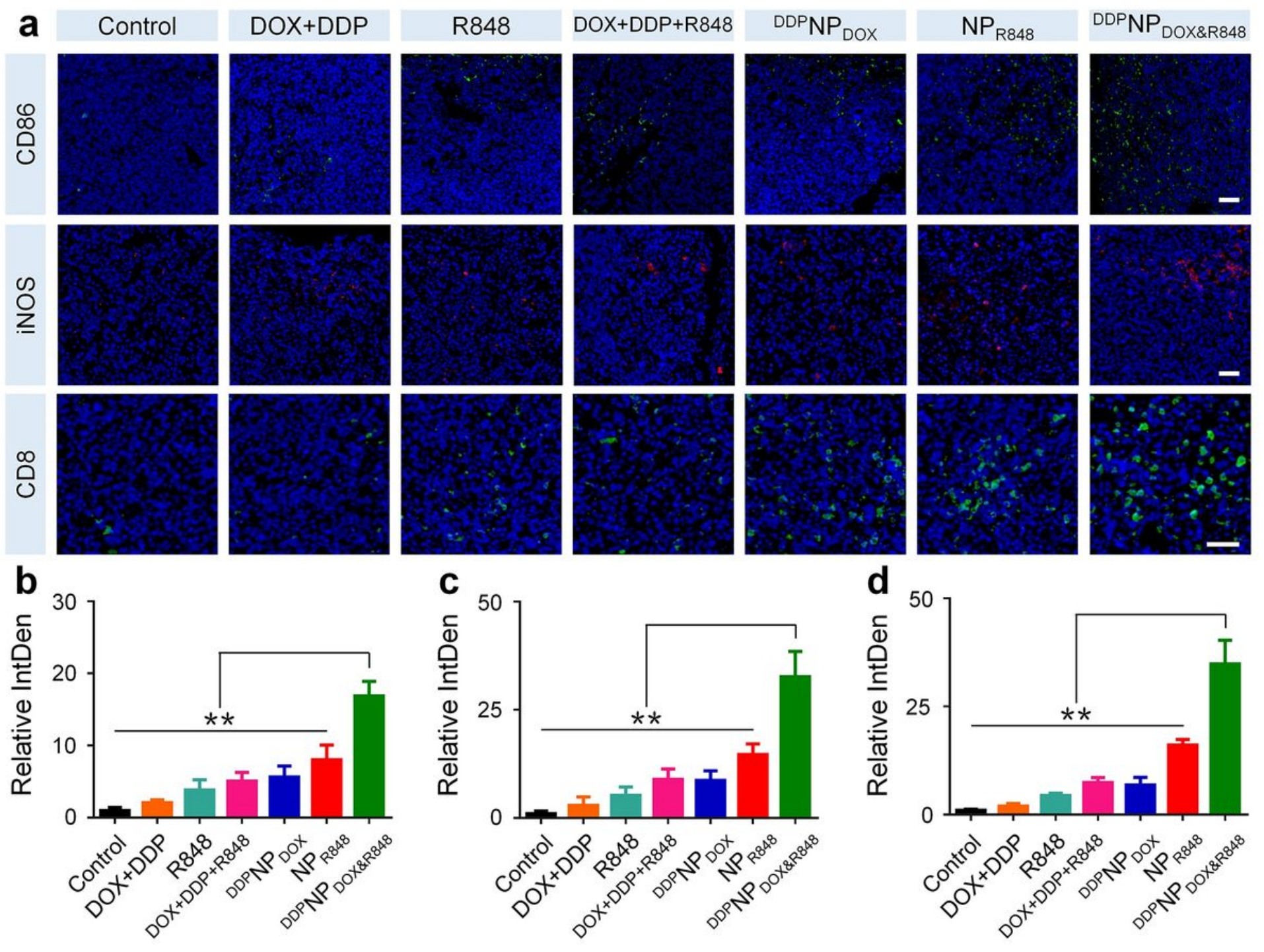

Figure 5

Immune response in vivo a Immunofluorescence (CD86, iNOS, and CD8) analyses and b - $d$ the relative optical densities of tumor tissue sections after different treatments. Scale bars: $50 \mu \mathrm{m}$. Data are presented as the mean $\pm S D(n=3$ for $b-d ; * * P<0.01)$. 


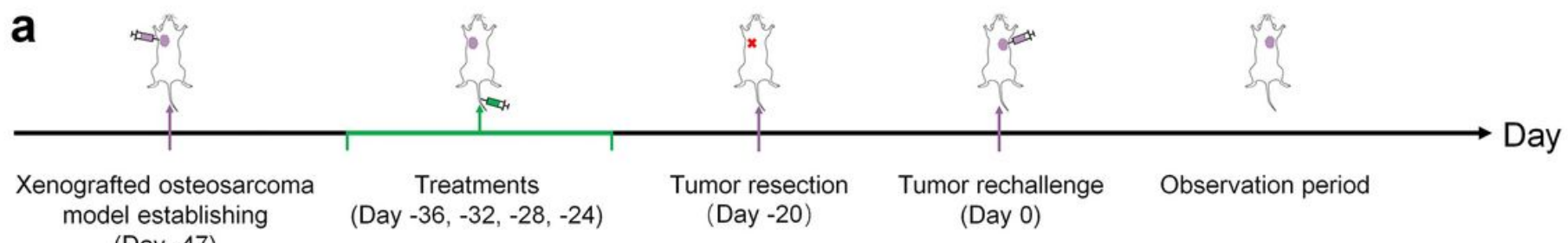
(Day -47)
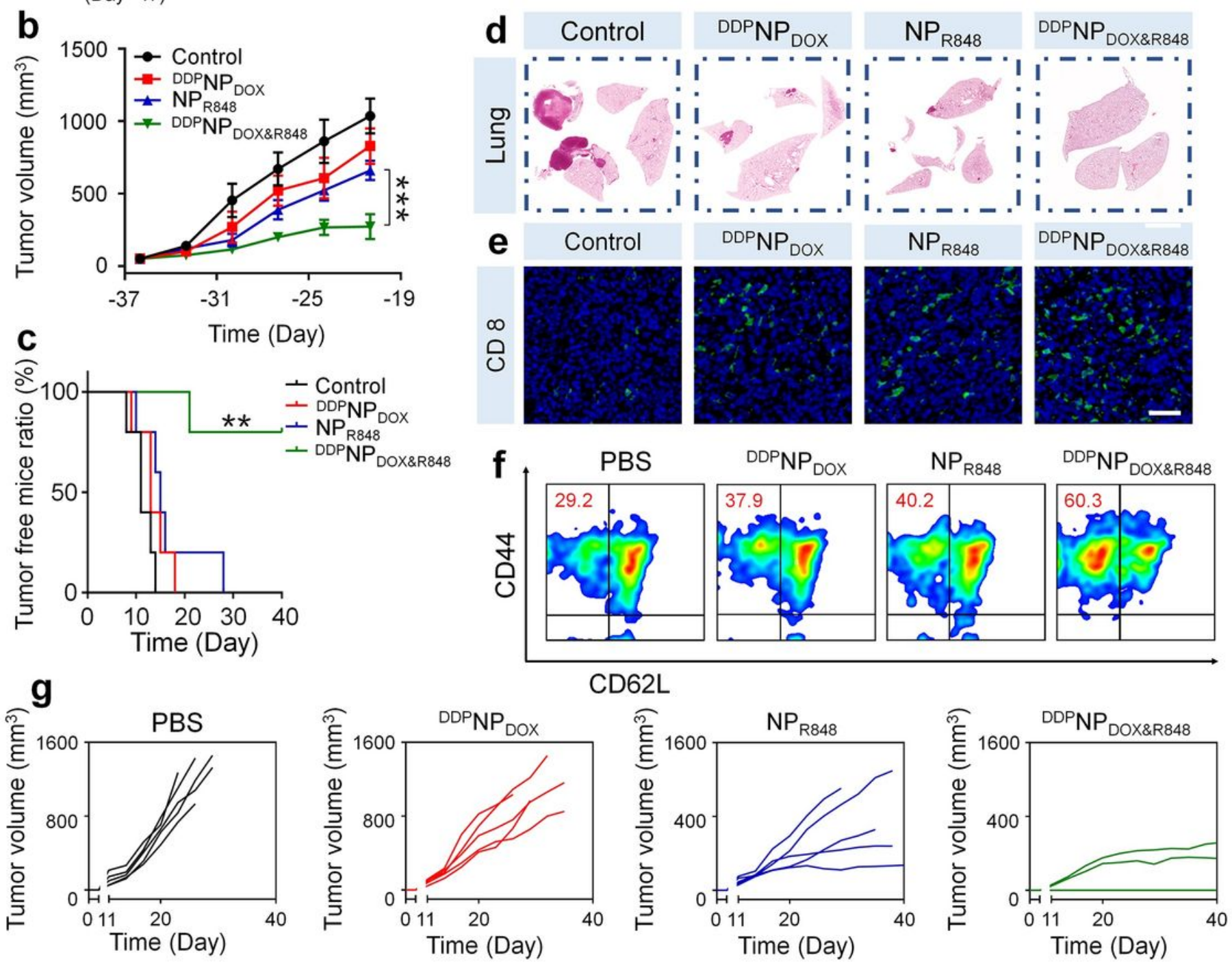

\section{Figure 6}

Long-term immune memory effect a Experimental schedule. $\mathrm{b}$ The primary tumor volume and c tumor free mice ratio of mice treated with PBS, DDPNPDOX, NPR848, and DDPNPDOX\&R848. $d$ H\&E staining analysis of lung metastasis in mice in different groups. e l3unofluorescence (CD8) analyses of tumor tissue sections after different treatments. Scale bars: $50 \mu \mathrm{m}$. $f$ The percent of TEM cells in spleens of the mice with different treatments were analyzed by flow cytometry (gated on CD3+ CD8+ T cells). g Individual tumor growth kinetics of the rechallenged distant tumors in mice with different treatments. Data are presented as the mean $\pm S D\left(n=8\right.$ for $b$ and $n=5$ for $c$; $\left.{ }^{*} P<0.01\right)$. 


\section{Supplementary Files}

This is a list of supplementary files associated with this preprint. Click to download.

- GraphicAbstract.docx

- Additionalfiles.docx

- Scheme1.tif 